\title{
ANIMAL EXPERIMENTATION IN STUDYING ADDICTION TO THE NEWER SYNTHETIC ANALGESICS
}

\author{
BY M. H. SEEVERS \\ Department of Pharmacology, University of Michigan, Ann Arbor, Michigan
}

\begin{abstract}
THE term addiction, when applied to the syndrome resulting from 1 the prolonged use of morphine and its congeners in man, by common usage involves three principal components, psychic dependence, physical dependence, and acquired tolerance. In view of the fact that the newer synthetic analgesics produce pharmacological effects, many of which are qualitatively similar to those of morphine and its derivatives, it is assumed, for purposes of this discussion, that morphine should stand as the drug of comparison, and that information regarding these three not easily dissociable qualities which constitute addiction to morphine must be obtained for each new agent of this type before it may be safely used clinically.

It is clear that clinical facilities for evaluating addiction liability are inadequate to keep pace with the rapid development of the newer synthetic analgesics. This being the case, and recognizing that the final evaluation of addiction liability of any compound proposed for clinical use must be determined in the human species, only that evidence which relates to the following question will be presented and discussed here: Does any infrahuman species exist which parallels normal man in its ability to develop "addiction" when chronically poisoned with morphine, its congeners, and the newer synthetic analgesics, and, if so, is this parallelism sufficiently striking that this species could be used as a reliable test object for the preliminary screening of new compounds? Since comparatively little work has been done in this field with the newer analgesic agents, a large share of the following discussion must center about morphine.
\end{abstract}

\section{Psychic Dependence}

At the outset, it should be clearly stated that the term "addiction," when applied to the condition resulting from chronic administration of morphine to infrahuman animal species, must have a more limited and specific connotation than when such a term is applied to the human addict. It is, perhaps, unfortunate that the term "psychic dependence" as it applies to morphine addiction in man has, in the broadest and most widely used sense, come to imply two differing but related factors: $(a)$ The characteristic and inherent pre-addiction urge of certain individuals to seek "euphoria" as a manifestation of an existing neurosis or psychosis. (Pescor ${ }^{1}$ found 96.2 per cent of 1,036 addicts at the Lexington Hos- 
pital to be either psychopathic or suffering from some neurosis prior to addiction.) (b) The psychosomatic conditioning established by prolonged administration of the drug which involves anticipation not only of the thrill, but also the mental relief from impending or actual physical symptoms of withdrawal.

Whereas certain higher animal species become conditioned to accepting the drug without the usual resistance and may even learn to associate the administration of the drug with the relief of the symptoms of abstinence, no counterpart of the manifestation of pleasure or "euphoria" obviously derived by addicts from repetitious use of these compounds has been observed in any animal species thus far studied.

Spragg $^{2}$ has shown that the chimpanzee will make an objective choice of the syringe over food during withdrawal, and the author has observed behavior in the rhesus monkey which leads him to believe that this animal can make a similar association. Although these observations in animals are of considerable interest as they relate to item $b$ above, it seems quite clear that it would be futile to attempt to transfer such observations into the clinic or use them as a basis for deductions or predictions regarding $a$, i.e., those qualities in the drug which would induce "euphoria," satisfy the "craving" of the inebriate type of personality, or appeal to the confirmed addict already conditioned by his previous experiences with drugs of this type.

Both meperidine and methadone have been administered to monkeys for fairly long periods of time without any evidence of desire on the part of the animals, even during withdrawal of these drugs. Such information should not, however, lead to the inference that addicts would not obtain a pleasurable sensation from the use of these drugs, a fact which has already been clearly established for miethadone in the clinic. For practical purposes, then, clinically applicable information from animals relating to addiction liability is limited to studies of tolerance and physical dependence.

\section{Physical Dependence}

Physical dependence to morphine can be established in numerous animal species ${ }^{3}$ including the mouse, rat, guinea pig, rabbit, cat, dog, monkey, and chimpanzee. The nature of the signs observed is dependent upon the physical characteristics of the species, and the phylogenetic development of the central nervous system, generalized "hyperirritability" being the only constant sign of abstinence in the lower species. In the smaller animals, wide individual variation in intensity of signs is noted, even after prolonged administration of large doses. Attempts have been made to use small animals for screening purposes. Barlow's method of using an increase in pre-injection irritability in the rat has been reported upon favorably. ${ }^{4,5} \mathrm{~A}$ wide variation in individual response was noted, a factor which in our hands greatly limits its value as a screening method, although it has not been applied to a study of the newer 
agents. Recently Phatak, Maloney, and David ${ }^{6}$ suggested the use of the hyperglycemic response of the rabbit for estimating addiction potentialities of analgesic compounds, and made observations on a group of methadone congeners. Unfortunately, the rabbit does not show satisfactory or reproducible abstinence phenomena during morphine withdrawal, and man does not obtain a hyperglycemic response to methadone. The author believes that any objective method, to be useful for comparative purposes, must involve signs which are demonstrable in man as well as in the animal under study. This statement would apply to changes in weight, temperature, blood sugar, variations in contractility of smooth muscle, circulatory alterations, or any other objective signs.

Whereas small animals may be used satisfactorily for studies of tolerance development, and probably for certain studies regarding mechanism of addiction, the author believes that only the dog and the monkey show signs of withdrawal which are sufficiently comparable to those observed in man to be reliable for screening and for the evaluation of new drugs. In view of the limited space available here, an attempt will be made only to compare these two species.

The Dog. Many observations have been made on this species, particularly with morphine. ${ }^{3}$ The abstinence syndrome is, in general, similar to that noted in man in so far as signs can be compared in view of the anatomical dissimilarities of the two species. Unfortunately, wide individual variation in response exists in different animals irrespective of dosage or duration of poisoning. Codeine $e^{7}$ does not induce physical dependence, although signs of abstinence have been noted with dihydromorphinone. ${ }^{8}$ Although tolerance studies have been made with heroin, no data have been published concerning physical dependence in this species.

Barlow gave 8 dogs $75 \mathrm{mg} . / \mathrm{kg}$. of meperidine orally once daily for ten months; 4 dogs $15 \mathrm{mg} . / \mathrm{kg}$. intramuscularly every 8 hours for 28 days; and 7 dogs $4 \mathrm{mg} . / \mathrm{kg}$, intramuscularly every two hours day and night for 5 days. Other than the acutc effects of the drug noted following administration, which included salivation, muscle tremors, spasticity, anorexia and weight loss, and an intense dislike for the drug which increased as the experiment progressed, no untoward signs were observed and no signs of abstinence were detected on withdrawal.

Scott and his co-workers ${ }^{10,11}$ did not note any signs of withdrawal in dogs administered methadone for several weeks. Wikler and Frank ${ }^{12}$ gave 1 to $2 \mathrm{mg} . / \mathrm{kg}$. of methadone 4 times daily to dogs, increasing the dose gradually to $5 \mathrm{mg} . \mathrm{kg}$., and continued the experiment for 10 weeks. Abrupt withdrawal revealed a marked abstinence syndrome characterized by restlessness, severe muscle tremors, fever, tachycardia, vomiting, hyperpnea, hydrophilia, and loss of weight, which appeared within 10 hours, reached a maximum in 24 hours, and subsided almost completely 
in 48 hours. Similar results were obtained in chronic spinal dogs and one chronic decorticated dog.13 In summary, Wikler states, "Quantitatively, signs of abstinence from methadon were easier to produce (could be developed in 1 month as compared with 2 or 3 months with morphine), came on more rapidly (apparent in 9 hours compared with 22 hours with morphine) and were more severe."

The Monkey. The abstinence syndrome in the rhesus monkey is objectively quite similar to that noted in man. ${ }^{14}$ Whereas individual variations exist in this species, and the observer must familiarize himself with the personality characteristics of each animal prior to addiction in order to make a satisfactory evaluation of abstinence phenomena (as is also the case with the dog), the picture is more uniform and more constantly reproducible than with the $\mathrm{dog}$ or any animal other than the chimpanzee, As in man, the monkey can exert wilful control over signs of abstinence. This may be related, in part, to fear of the attendant, whose entrance into the room produces changes in behavior which mask the signs of abstinence. When the animal is observed during abstinence through a sound-proof, "one-way vision" glass window, the true picture of abstinence is revealed. This technique, recently adopted in this laboratory, has greatly enhanced the reliability of our observations.

Heroin and dihydromorphinone produce signs of abstinence comparable to morphine, whereas codeine produces only minimal signs in this species. ${ }^{15}$

The only observations on meperidine known to the author to have been made in this species are those of Barlow. ${ }^{9}$ He administered meperidine to 14 rhesus monkeys in dosage of $14 \mathrm{mg}$. $/ \mathrm{kg}$. orally once daily for 10 months; to 5 monkeys $15 \mathrm{mg} . / \mathrm{kg}$. intramuscularly every 8 hours for 28 days; and to 7 monkeys $4 \mathrm{mg}$. $/ \mathrm{kg}$. intramuscularly every 2 hours for 5 days. Whereas these doses produced marked acute effects, no signs of abstinence were noted on withdrawal.

Woods, Wyngaarden, and Seevers ${ }^{16}$ administered methadone in an initial dose of $5 \mathrm{mg}$. $/ \mathrm{kg}$. once daily subcutaneously to monkeys. This dose was increased in 24 to 26 days to the maximum tolerated acute dose (11 to $13 \mathrm{mg} . / \mathrm{kg}$.), and then continued at this level for 75 to 96 days. No signs of abstinence were detected on withdrawal, although controls on morphine demonstrated the characteristic picture of animal addiction to this drug.

Cochin, Gruhzit, Woods, and Seevers ${ }^{17}$ repeated these experiments recently, but administered the drug 3 times daily in a dosage of $7 \mathrm{mg} . / \mathrm{kg}$. (total daily dose of $21 \mathrm{mg} . \mathrm{kg}$.) for four and one-half months. This represented the maximum tolerated dose at this interval of administration. Controls with morphine were given $50 \mathrm{mg} . / \mathrm{kg}$. thrice daily. Signs of abstinence from methadone, if they actually existed at all, were minimal. Slight pilomotor activity was noted at 36 hours. The animals were more active at 36 hours, but this appeared to be merely the release from metha- 
done depression and a return to normal excitability rather than a state of hyperexcitability. Anorexia was not noted as was the case with morphine withdrawal, and no significant weight change occurred. In contrast, the controls on morphine showed the most marked signs of withdrawal ever noted by the author. This was probably related to the rate of administration, since virtually all previous experiments in the monkey have been made with single daily dosage. One animal, after a period in which he exhibited all the classical signs of withdrawal, lapsed into a state of profound exhaustion, refused food and water, became intensely dyspneic, and, after some struggling incident to the removal from the cage after 76 hours for movie recording, became intensely cyanotic and died within 15 minutes. This death was evidently of circulatory type, the heart being acutely dilated at autopsy. This animal was otherwise in good physical state, had not lost weight, and no other pathology was revealed at autopsy.

\section{Tolerance}

Whereas acquired tolerance is always demonstrable and a part of the picture of morphine addiction, its exact relationship to physical dependence and psychic dependence is not clearly defined. That the acquisition of tolerance is not necessary to the establishment of psychic dependence to a drug is clearly shown in the case of cocaine, since the latter may be clearly established without any evidence of tolerance development. Conversely, marked tolerance may be acquired to other compounds, such as the organic nitrites, without associated psychic or physical dependence.

It is evident that various body mechanisms and tissues differ qualitatively and quantitatively with respect to tolerance development.

Blood vessels become rapidly tolerant to morphine, as was first shown by Schmidt and Livingstone. ${ }^{18}$ Recently, Shideman and Johnson ${ }^{19}$ have shown that some vascular tolerance can be developed to meperidine and methadone, and they have compared it with morphine in the dog. In a general way, this "acute tolerance" parallels the development of "chronic tolerance" to the sedative or narcotic action of these three drugs, both appearing rapidly with morphine, more slowly with methadone, and poorly and incompletely with meperidine. Whether this method can be used for screening to predict tolerance development awaits more extended studies with a greater number of new compounds.

Contrary to the situation with respect to physical dependence, small animals may be used satisfactorily for estimation of tolerance to the analgesic and general sedative action of these drugs.

Tolerance to the analgesic action of morphine and its derivatives is readily established in most species of animals. The author is not aware of carefully controlled studies on animals with meperidine regarding tolerance to its analgesic effects. Tolerance develops in former morphine 
addicts, ${ }^{20}$ but this is not a prominent feature of its clinical use in nonaddicts. ${ }^{21}$ Tolerance to the analgesic action of methadone has been developed in the mouse, ${ }^{22}$ the rat, ${ }^{11,}{ }^{23}$ the $\mathrm{dog},{ }^{12}$ and in man. ${ }^{22}$

Tolerance to the general depressant action is readily established for morphine and its derivatives in all species. ${ }^{3}$ Some tolerance is developed to this property for meperidine in rats and dogs although it is not marked..$^{9}$ Tolerance to the sedative action of methadone is readily developed in the rat, ${ }^{10}$ in the $\mathrm{dog},{ }^{12}$ slowly in the monkey ${ }^{16}$ and man, ${ }^{22}$ especially to larger dosages.

Acquired tolerance does not raise the lethal dose of morphine derivatives in any animal lower than the monkey, since death is due to convulsions rather than respiratory depression and tolerance is not developed to this stimulant action. This is probably true also of meperidine and methadone, since these drugs also produce death of a convulsant type in smaller animals. Since some monkeys and all men die of primary respiratory depression from morphine, it is easy to establish tolerance to this respiratory depressant effect of morphine, heroin and Dilaudid (not codeine), and consequently to what would otherwise be a lethal dose. The monkey (and presumably man) always succumbs to respiratory failure with lethal doses of methadone.$^{16}$ Very little, if any, tolerance is developed to this respiratory depressant effect and a small increment in dosage above the maximum tolerated single dose, 12 to $15 \mathrm{mg}$. $/ \mathrm{kg}$., will result in respiratory failure. We ${ }^{17}$ have obtained some suggestive evidence, which will require further study and confirmation, that respiratory tolerance to morphine confers crossed tolerance to methadone. By mistake, morphine-addicted animals were given $25 \mathrm{mg} . / \mathrm{kg}$. of methadone, a dose which we believe to be certainly lethal. Whereas these monkeys were treated after about thirty minutes with caffeine, it is believed that they would not have succumbed without such treatment. It is interesting, in this regard, that all of the evidence which indicates a lowgrade respiratory tolerance to methadone in man has been obtained on addicts with a highly developed tolerance to morphine.

The author believes that predictions regarding addiction liability cannot be made at this time on the basis of tolerance studies alone, although it seems clear that the degree of addiction liability with morphine, meperidine, and methadone parallels roughly the degree of tolerance development, especially to the narcotic action of large doses of these drugs.

\section{Summary}

In considering the problem of predicting addiction liability in man from animal experiments, the conclusion is inevitable that the only reliable criterion upon which to base a decision is the establishment or lack of establishment of physical dependence. Up to the present time, no evidence is available which will refute the view long held by the author that the monkey is the best animal species available practically for the 


\section{Annals: New York Academy of Sciences}

reliable prediction of addiction liability in the "normal" human subject. This statement is based upon the following facts which hold for the normal monkey and normal man.

(a) The signs-and, judging from the actions of the monkeys, the symptoms-of abstinence from morphine, their time of appearance, their intensity, and duration, are for practical purposes identical in both species.

(b) The intensity of abstinence phenomena with the morphine derivatives, heroin, Dilaudid, and codeine are quantitatively similar.

(c) Signs of abstinence from meperidine are minimal.

(d) Complete and adcquate substitution is readily established from morphine to its derivatives and to methadone in both the monkey and human addict.

(e) Tolerance development to these various drugs is qualitatively and quantitatively similar in both species.

$(f)$ Physical dependence to methadone, if present at all, is slight and slowly developed in individuals not previously addicted to morphine.

It is hardly to be expected that studies of addiction liability in the "normal" monkey could be compared directly with studies made in human individuals who have been previously addicted to morphine. Such individuals not only represent a selected group who are psychiatrically inferior, but they have in addition been conditioned or "sensitized" to the whole experience of addiction, including their own selective interpretation of "euphoria."

The question is still pertinent, and as yet unanswered, whether prolonged addiction to morphine leaves a permanent physical as well as a mental residue even after apparent "cure." Thus, we do not know whether it is safe to make predictions, on the basis of addiction and substitution studies in actual or in "cured" morphine addicts, regarding the addiction liability, or even the "euphoria"-inducing qualities of new and chemically different compounds, if such predictions are to apply to psychiatrically "normal" individuals. It is probable that no studies on animals will ever solve the problem of whether a chemical compound is potentially addicting for "constitutional addicts." The published evidence seems to support the view that, excluding this group of individuals, normal human subjects, like normal monkeys (see TABLE 1), develop very little psychic or physical dependence to those synthetic analgesics, particularly meperidine and methadone, the only compounds which have thus far been even partially evaluated.

If such are the actual facts, it then scems evident that our problem in the evaluation of new compounds should be much broader than the mere search for a substance which will give perfect analgesia to the "normal" human subject without the development of the syndrome which we term addiction. We should emancipate our thinking from the concept that the capacity of a chemical substance to produce "euphoria" is inevitably an undesirable quality and make a positive and specific 


\section{TARLE 1}

Physical Dependence to Analgesic Drugs

\begin{tabular}{|c|c|c|c|c|}
\hline Drug & $D \circ g$ & Monkey & $\begin{array}{c}\text { "Normal" } \\
\text { human subjects }\end{array}$ & Human addicts \\
\hline Morphine & $+++(3)$ & $++++(3)$ & $++++(3)$ & $++++(3)$ \\
\hline Heroin & $\left\{\begin{array}{c}\text { not } \\
\text { reported }\end{array}\right\}$ & $++++(15)$ & $++++(3)$ & $++++(3)$ \\
\hline $\begin{array}{l}\text { Dihydro- } \\
\text { morphinone } \\
\text { Codeine } \\
\text { Meperidine }\end{array}$ & $\begin{array}{c}++(8) \\
\text { none }(7) \\
\text { none }(9)\end{array}$ & $\begin{array}{c}++++(15) \\
+(15)^{*} \\
\text { none }(9)^{*}\end{array}$ & $\begin{array}{c}++++(3) \\
?(3) \\
?(21)\end{array}$ & $\begin{array}{c}++++(3) \\
+(3) \\
+(21)\end{array}$ \\
\hline Methadone & $\left\{\begin{array}{c}++++ \\
(10-24 \text { hours }) \\
(12)\end{array}\right\}$ & $+?(16)^{*}$ & $\left\{\begin{array}{c}\text { not } \\
\text { reported (22) }\end{array}\right\}$ & $\left\{\begin{array}{c}++(\text { fifth to } \\
\text { ninth day) (2Q) }\end{array}\right.$ \\
\hline
\end{tabular}

- With maximum tolerated doses.

search for compounds which, devoid of the ability to induce physical dependence, will satisfy that large group of constitutionally inferior individuals now classified as criminals because they yield to an inherent psychic drive ot under their control.

\section{Bibliography}

1. Pescor, M, J. 1939. Public Health Rep. Suppl. 155.

2. Spragg, S. D. S. 1940. Comp. Psychol. Monogr. 15: 132.

3. Krueger, H., N. B. Eddy, \& M. Sumwalt. 1941. Pub. Health Rep. Suppl. 165.

4. Himmelsaach, C. K., G. H. Gerlach, \& E. J. Stanton. 1935. J. Pharm. \& Exp. Therap. 53: 179-188.

5. Eddy, N. B., \& C. K. Himmelsbach. 1936. Pub. Health Rep. Suppl. 118.

6. Phatak, N. M., J. Maloney, \& N. David, 1948. Fed. Proc. 7: 247.

7. Tatum, A. L., M. H. Seevers, \& K. Col.tins. 1929. J. Pharm. \& Exp. Therap. 36: 447.

8. Eddy, N. B., \& J. S. Reid. 1934. J. Pharm. \& Exp. Therap. 52: 468-493.

9. BarLow, $O$. W. Personal communication of unpublished experiments.

10. Scotr, C. C., \& K. K. Chen. 1946." J. Pharm. \& Exp. Therap. 87: 63.

11. Scotr, C. C., K. S. Konlstaedt, E. B. Robbins, \& F. W. Israec. 1947. Fed. Proc. 6: 370.

12. Wikleh, A., \& K. Frank. 1947. Fed. Proc. 6: 384.

13. Wikler, A. 1945. Fed. Proc. 4: 141; 1946. Ibid. 5: 215.

14. SEevers, M. H. 1936. J. Pharm. \& Exp. Therap. 56: 147.

15. Seevers, M. H. 1936. J. Pharm. \& Exp. Therap. 56: 157.

16. Woons, L. A., J. B. Wrygaardex, \& M. H. Seevers. 1947. Proc. Soc. Exp. Biol. \& Med. 65: 113.

17. Cochin, J., C. C. Grunzit, L. A. Woons, \& M. H. Skevers. (To be published.)

18. Sснмiot, C. F., \& A. E. Livingston. 1933. J. Pharm. \& Exp. Therap. 47: 443.

19. Shroeman, F. E., \& H. T. Johnson. 1948. J. Pharm. \& Exp. Therap. 92: 414.

20. Andrews, H. L. 1942. J. Pharm. \& Exp. Therap. 75: 338.

21. Batterman, R. C., \& C. K. Нtmmelsbach. 1943. J.A.M.A. 122: 222.

22. Isbell, H., A. WikLer, N. B. Edey, J. L. Wilson, \& C. F. Moray. 1947. J.A.M.A. 135: 888.

23. LEwIs, J. Personal communication. 


\section{Discussion of the Paper}

\section{Dr. Abraham Wikier (U.S. Public Health Service Hospital, Lexington,} Kentucky):

Although Dr. Seevers's paper deals primarily with animal experimentation, I should like to comment first on his conclusions as they apply to man. Dr. Seevers states that conclusions derived from studies on "psychiatrically inferior" individuals previously addicted to morphine cannot be expected to apply to "normal" persons not previously addicted. In this I should like to concur, if we consider the addiction problem only in its relation to "normal" persons. However, the normal well-adjusted, mature person is not likely to become a habitual drug addict. In our society, with legal and social attitudes such as they are, drug addiction becomes a public health problem chiefly in relation to those individuals whose emotional need for morphine, or drugs like it, is so strong that it overbalances the personality defenses (e.g., "super-ego" structure) against addiction. Prominent in this group are the extremely infantile, narcissistic individuals who constitute the bulk of those post-addicts who volunteer for addiction studies. From a public health standpoint, it appears quite appropriate to study drug addiction in such individuals.

In commenting on the animal work which Dr. Seevers has discussed, I should like to limit my comments to some of the neurophysiological aspects, with particular reference to morphine and methadone, since my interest in addiction problems has been largely in this area. First, the terms "psychic" and "physical" dependence have acquired various connotations and should be defined more precisely. Thus, a distinction between "psychic" and "physical" cannot be made on the basis of objectivity or subjectivity of the symptom or sign. Tachycardia, vomiting, even fever, may be "psychic" in origin, while purposive behavior may be "physical" in origin, as has been demonstrated so strikingly by Richter's work on self-regulatory behavior in animals. Defined with reference to genesis, the distinction between "psychic" and "physical" can be made on the basis that the former is related to factors with symbolic significance varying in complexity, whereas the latter is related to factors with little or no symbolic significance. Viewed in these terms, it becomes apparent that theoretically, at least, it is not possible to distinguish between those aspects of addiction which are "psychic" in origin and those which are "physical" in intact man, or even in intact animals. Clinical experience has shown that the morphine abstinence picture is definitely related to the personality of the addict. Likewise, in our investigations, the effects of morphine on adaptive behavior in intact dogs have been shown to depend on the "personality" of the animal. Perhaps this accounts for the great variability in the abstinence picture from dog to dog, since this species exhibits a wide range of personality types.

True "physical dependence" in the sense described can, however, be studied in animal preparations in which a portion of the central nervous 
system is isolated from the remainder, as in chronic decorticated and chronic spinal dogs. In such preparations, the capacity for symbolization is markedly impaired, and the reactions to various stimuli are stereotyped and predictable with accuracy. Thus, in the decorticated animals, circling activity, irritability, temperature, pulse, respirations, and tooth pain-reaction threshold can be measured accurately. In the chronic spinal preparations, the knee jerk, ipsilateral extensor thrust, ipsilateral flexor reflex, and crossed extensor reflex, as well as spontaneous activity of the hindlimbs can be recorded reliably. During addiction to morphine or methadone, tolerance is manifested to the action of these drugs on certain of the reactions mentioned, and during withdrawal, striking hyperactivity and other changes occur with great regularity and predictability in both types of preparations. The preparation and preservation of the chronic decorticated animals is a difficult procedure. However, chronic spinal dogs can be prepared in a one-stage operation. They require close attention during the first postoperative month, but after 4 to 6 weeks these preparations survive for years with a minimum of care, chiefly directed to keeping the hindlimbs and perineal regions dry. The reflexes attain a stable level in this period of time, and can be recorded very simply with an "isotonic" a pparatus utilizing "natural" stimuli eliciting a maximal response. With this technique, the changes which occur spontaneously over a period of as long as 6 months are negligible compared to the effects of drugs during addiction studies.

Although the study of "physical" dependence can be facilitated by such techniques, the problem of species differences still remains. Whether or not the techniques described can be applied to monkeys will be determined by future investigations. That it would be of advantage to make such studies is apparent from Dr. Seevers's excellent review of the problem. 